\title{
Testing Technique and Materials Component of Green High Performance Concrete
}

\author{
Feng-De ZHANG ${ }^{1, a}$, Qing-Hui LAI ${ }^{2, b}$ and Zheng-Jun WANG ${ }^{2, c, *}$ \\ ${ }^{1}$ Heilongjiang sanjiang engineering construction administration, 150081, China \\ ${ }^{2}$ College of Water Conservancy and Electric Power, Heilongjiang University, 150080, China \\ aZZhangfengde626@126.com, 'b18765855696@163.com, 'wzsir@163.com, \\ *Corresponding author
}

Keywords: Green High Performance Concrete, mineral admixture, water reducing agent, the nondestructive detection method.

\begin{abstract}
Ordinary concrete is four components, and the six components of green high performance concrete, more than the ordinary concrete admixture and high efficiency water reducing agent. The strength of green high performance concrete fast nondestructive testing is an important aspect of development of its application. Admixtures can improve concrete workability and improve resistance corrosion; especially it can inhibit alkali-aggregate reaction. Admixtures are paid attention to researchers in this field. Concrete water-reducing agent is admixture of the main part. In the case of keeping liquidity, it can make water consumption reduce, so the concrete strength and durability can be improved.without destroying the high performance concrete structure, through the method of nondestructive testing, can detect accurately the compressive strength.
\end{abstract}

\section{Introduction}

High performance concrete is a kind of new high-tech concrete; it must adopt low water-binder ratio, adequate fine mineral mixture, and high active admixture besides applying in high grade cement, aggregate and water. Furthermore, high performance concrete has some performance including of durability, workability, all kinds of mechanical property, applicability, volume stability and economic advisability [1]. Admixture water reducing agent play important roles in degrading heat of hydration, improving up concrete workability, enhancing durability and reducing cost etc. Concrete admixture is a kind of material that can improve concrete performance when it is blended in concrete mixture. At present, normal concrete admixtures involve in fume ash, granulated blast furnace slag and pozzolanic material. Water-reducing agent is a kind of admixture that can reduce water consumption would improve the strength of concrete in the same conditions of concrete workability and cement contents. At present, several kinds of water-reducing agents are commonly used for: water-reducing agent of lignin sulfonic acid sodium salt, superplasticizer of naphthalene, water-reducing agent of aliphatic efficient, water-reducing agent of amino efficient, water-reducing agent of poly-carboxylic acid efficient, etc in the market [2-7]. At the same time, nondestructive testing technology in concrete engineering application is relatively mature and has been widely used, such as ultrasonic method, rebound method, ultrasonic rebound method, and has formed the corresponding standard, countries are established, and the area curve for measuring strength of the green high performance concrete is different from ordinary high performance concrete, its strength and durability have changed greatly.

\section{Admixture for High Performance Concrete}

GHPC (Green High Performance Concrete) is the development direction of the concrete, and all concrete will be GHPC if it is green concrete [8]. Composite admixture High performance concrete admixture that improves mainly the construction and application performance of concrete is a new type of material, and can improve the durability of concrete.

Fly ash, Coal gangue, silica fume metakoalin are mineral admixtures. Silica fume Silicon fume 
has been extensively applied because it has extremely high fineness and ash role in high performance concrete; however, this material is the limited resources available and higher cost. Peyun CHI et al [9] studied the chemical composition of fly ash, physical properties and particle size distribution and by adding 40\% fly ash of high performance concrete performance. Faguang Leng [10] elaborated on China's coal gangue resources at home and abroad, the research and application of coal gangue, analyzed the gangue cement concrete performance, put forward new direction about further research and utilization of coal gangue. Metakaolin played mechanism to the similar silicon ash. Admixture that is mixed with metakaolin can be prepared with good workability of HPC. In mechanical performance, metakaolin can completely rival with silicon fume [11].

There are also biomass admixtures such as straw ash, rice husk ash,etc. Nguyen Van Tuan et al [12] proceeded in useful exploration using rice husk ash in high performance concrete admixtures, In the proper conditions, rice husk ash that can not only improve the strength of concrete but also reduce the permeability increase durability of concrete has high active volcanic ash [13].

\section{Water-reducing Agent for High Performance Concrete}

Application of Superplasticizer is a major milestone of technology development of concrete. Superplasticizer has high rate of decreasing water, can promote the hydration in the early hydration reaction. JunHua Tan [14] compared detail to the different characteristics of efficient water-reducing agent and its influence on the performance of the concrete.

Water reducing agent of Lignin sulfonic acid sodium is composite into early strength agent, antifreeze, pumping agent, etc. Liquid admixture that is composite with effective naphthalene water-reducing agent has basically no precipitation produce. The production accords with national standards of concrete admixtures. is suitable for mass concrete, concrete of big liquidity degree, pumping concrete, commercial concrete, concrete construction in summer. High performance water-reducing agent of poly-carboxylic acid is a kind of optimal a concrete. Alkali content is extremely low, which can effectively prevent the happening of the alkali aggregate reaction, product stability is better. Its Mechanism includes mainly Dispersion, lubrication, and resistance function, etc. Because of strong dispersion effect to cement, it can greatly increase fresh cement liquidity and concrete slump. Naphthalene superplasticizer is the chemical synthesis of high efficient water-reducing agent of non inducing air. It has very good using effect for Preparation of flow state concrete, having cast-in-situ concrete of high strength requirements and pre-fabricating components, improving the performance of concrete. However, Naphthalene sulfonate-formaldehyde is poisonous and corrosive, have also adverse effects to the architecture health of workers. Loss of concrete slump is rapid if naphthalene water-reducing agent is simply added.

\section{Testing Technique of strength of High Performance Concrete}

There are many methods for nondestructive testing of concrete, such as rebound method, ultrasonic method, Ultrasonic rebound synthetic method, electromagnetic wave method and so on.

Ultrasonic rebound synthetic method is very widely used a nondestructive testing method. First, data acquisition The experiment adopted standard specimens, two relative pouring sides of each specimen act as testing plane of rebound detection, there eight testing points spreading in each testing side, other two relative pouring sides act as bearing planes testing compressive strength of destructive experiment. After rebound detection was accomplished, compressive strength of the specimen would be tested at once. On both sides of each specimen rebound test, a total of sixteen points. The rebound representative values were determined after 16 point two minus 3 Ma Xima values and 3 minimum and 10 numbers, and solve their average. Then establish the model relationship with the corresponding strength value. 


\section{Conclusions}

At present, admixture of high performance concrete are mainly slag, fly ash, zeolite, silicon fume, etc. However, the existing mineral admixtures of high performance concrete are limited available resources, and higher cost. Biomass admixture has wide application prospect. Poly-carboxylic acid superplasticizer is water-reducing agent in the history of the third generation of products with low content, high decreasing water rate, good adaptability to cement. As a kind of most important concrete admixture, it is also widely used in recent years in civil engineering. Application of high performance concrete is more and more widely, the strength of fast nondestructive detection is very important

\section{Acknowledgement}

The paper was supported by The national natural science fund project(51678221), Education Department of Heilongjiang province (No.12521409) , Application technology research and development plan to guide project in heilongjiang province(GZ16B013), and science and technology project of Heilongjiang sanjiang engineering construction administration (HGZL/KY-01)

\section{References}

[1] Z.W.WU: submitted to Construction and Technique (1999). (In Chinese)

[2] D.F.Zhang, B.ZJu , S.F.Zhang, L.He, and J.Z. Yang: submitted to Carbohydrate Polymers (2007)

[3] P.F.G. Banfill: submitted to Construction and Building Materials 25 (2011) 2955- 2960

[4] Amanmyrat Jumadurdiyev, M. Hulusi Ozkul, Ali R. Saglamb, Nazmiye Parlak: submitted to Cement and Concrete Research (2005)

[5] J.H.Peng, J.D. Qu, J.X.Zhang, M.F. Chen,and T.Z.Wan: submitted to Cement and Concrete Research (2005)

[6] Z.W. Wu: submitted to Concrete and Cement Products(2000)

[7] D. F. Zhang, B. Z. Ju, S. F. Zhang, J.Z. Yang: submitted to Carbohydrate Polymers (2008)

[8] Z.W.WU: submitted to Concrete and Cement Product (2000). (In Chinese)

[9] P.Y.CHI, F.Y.LIANG, and S.K.LU: submitted to Science Research (2002). (In Chinese)

[10] F.G.LENG: submitted to Sichuan Building Scientific Research (2000). (In Chinese)

[11] D.M.WANG, S.K.HU, W.F.XIONG, Y.F.ZUO, X.H.LUO, Y.GAO, and Y.FU, in: The sixth national high strength and high performance concrete conference proceedings: 135-137

[12] V.T.Nguyen, Y.Guang, V. B. Klaas, L.A. F. Alex, and D. D. Bui: submitted to Construction and Building Materials (2011)

[13] P.K.Mehta: submitted to Advances in Concrete Technology. Second Edition. Published by CANMET.Edited by V.M.Malborra(1994)

[14] J.H.Tan: submitted to Shanxi Chemical(2010) . (In Chinese) 